\title{
Do frequent satisfying trips by public transport impact its intended use in later life?
}

\author{
Jonas De $\operatorname{Vos}^{1}$ (D) E. Owen D. Waygood ${ }^{2}$ (D) $\cdot$ Laurence Letarte $^{3}$ (D) $\cdot$ Mengqiu Cao $^{4,5}$ (D)
}

Accepted: 1 July 2021 / Published online: 15 July 2021

(c) The Author(s) 2021

\begin{abstract}
Previous studies have indicated that factors such as the built environment, attitudes and past behaviour can influence travel behaviour. However, the possible effect of travel satisfaction on travel mode choice remains underexplored, despite many studies focusing on travel satisfaction over the past years. It is likely that individuals experiencing satisfying trips with a certain travel mode will use this mode (more) frequently for future trips. In this study—using data from 984 students from Laval University, Canada-we analyse how satisfaction with public transport and the frequency of public transport use affect the intention to use public transport in later life stages. Our results indicate that public transport frequency, public transport satisfaction and the interaction between these two factors (i.e., the frequency of (dis)satisfying public transport trips) significantly affect people's intentions to use public transport in later life, although variations in effect sizes exist between different life stages. Making public transport more pleasant and increasing ridership of children and young adults (e.g., by giving them free public transport passes) may consequently result in a higher public transport frequency in later life stages. We argue that travel satisfaction can play an important role in the formation of habitual mode use, and that satisfying trips (if undertaken frequently) are likely to be repeated in the future.
\end{abstract}

Keywords Travel behaviour · Travel satisfaction · Habits · Public transport

Jonas De Vos

jonas.devos@ucl.ac.uk

1 Bartlett School of Planning, University College London, London, UK

2 Department of Civil, Geological, and Mining Engineering, Polytechnique Montréal, Montreal, Canada

3 Graduate School of Planning and Regional Development, Laval University, Quebec, Canada

4 School of Architecture and Cities, University of Westminster, London, UK

5 Department of Statistics, London School of Economics and Political Science, London, UK 


\section{Introduction}

Many studies have explored the determinants of travel behaviour and mode choice in particular. Studies - mainly from the 1990s and early 2000s - found that the residential location has an important effect on travel mode choice. People living in low-density suburbs tend to use the car for most trips, while those living in compact, mixed-use neighbourhoods regularly walk, cycle or use public transport (e.g., Cervero and Kockelman 1997; De Vos 2015; Frank and Pivo 1994; Ewing and Cervero 2001, 2010; Waygood et al. 2015). In the last two decades, evidence has accumulated that besides the built environment, attitudes can also impact the way people travel, and that a positive stance towards a certain travel mode can stimulate the use of that mode (e.g., Bagley and Mokhtarian 2002; Beirão and Cabral 2007; Heinen et al. 2011; Kitamura et al. 1997). These travel attitudes may also have an indirect impact on travel behaviour through residential location choice, since people may want to live in a neighbourhood enabling them to travel in a preferred way (known as transport-related residential self-selection) (Cao et al. 2009; Handy et al. 2005). Some studies have also indicated that the choice of travel mode is strongly affected by past (mode choice) behaviour, partly due to the formation of habits (Bamberg et al. 2003a; Gardner 2009). People may not always consciously choose a travel mode based on existing attitudes, but rather choose a mode that satisfied their needs in previous trips.

During the past decade, numerous studies have started exploring how people experience their travel and how satisfied they are with it. These studies have mainly focused on the determinants of travel satisfaction, such as travel mode choice and travel duration (e.g., De Vos et al. 2016; Morris \& Guerra 2015). Although some of them have suggested that satisfaction with a trip using a certain mode can positively impact the likelihood of a person using that mode again in the future, this effect remains underexplored (De Vos 2019). It is reasonable to assume that it is not only the satisfaction with a particular mode that influences its future use, but also the frequency of (dis)satisfying trips. In this study, we will therefore explore the effects of the frequency of public transport (PT) use, satisfaction with PT, and the frequency of (dis)satisfying PT trips on the intention to use PT in later life stages using data from students at Laval University in Canada. This paper is organised as follows. Section 2 gives an overview of studies that have analysed the effect of past behaviour and travel satisfaction on travel behaviour. In Sect. 3, the used data and key variables are described. Section 4 presents the found results, while a discussion and conclusion are provided in Sect. 5 .

\section{The effect of past behaviour and travel satisfaction on travel behaviour}

According to the theory of planned behaviour (TPB; Ajzen 1991), behaviour is reasoned and influenced-among others-by attitudes and intentions. The frequency of prior behaviour is only assumed to have an indirect effect on later behaviour (e.g., through perceived behavioural control and attitudes) (Bamberg et al. 2003b). However, multiple studies have found that past behaviour has a strong impact on later behaviour, and that behaviour is often habitual, i.e., repeated without a deliberate choice process (Aarts et al. 1998; Gärling and Axhausen 2003). Habits can have clear benefits, since searching for new alternatives can be mentally tiring and time-consuming, the expected benefits of alternatives can be uncertain, and repetition of past behaviour is generally easier and 
less risky (e.g., Gärling and Axhausen 2003; Zarabi et al. 2019). Some travel behaviour studies have found that travel mode choice is partly habitual. Gardner (2009), for instance, found that commute mode choice remains stable over time and that intentions to travel by car or bicycle did not affect the use of the respective modes in case of strong (car or cycling) habits. It is believed that a deliberate choice process occurs when habits are weak, while attitudes and intentions only have a limited impact on behaviour in case of strong habits (Klöckner and Matthies 2004; Triandis 1977; Verplanken et al. 1998). Verplanken et al. (1997), for instance, found that a strong habit of using a specific travel mode resulted in less-informed travel mode choices, and vice versa. An individual will not likely seek out additional information on other means of travel if they are satisfied with their current behaviour.

Although behaviour is often habitual, studies have found that a change in context can break travel habits. Some studies have found, for instance, that a temporary free PT pass can partly break car habits and increase PT use, in case of University students (Bamberg et al. 2003a; Fujii \& Kitamura 2003), University employees with full-time parking permits (Abou-Zeid and Ben-Akiva 2012), and randomly selected car owners (Thøgersen and Møller 2008). Other studies have found that people relocating to a new residential location are likely to change their mode choice (Zahrabi et al. 2019), more likely compared to those not moving (Verplanken et al. 2008). Walker et al. (2015) found that old travel habits decayed after a workplace relocation. Despite evidence suggesting that (travel) habits becoming less strong in case of a context change, multiple studies have indicated that frequently performing behaviour in stable contexts is unlikely to be spontaneously reconsidered and changed (e.g., Gardner 2009; Thøgersen 2006). In other words, past behaviour is likely to affect future behaviour in stable contexts.

Over the past decade, many studies have started analysing which emotions people experience while travelling and how they evaluate the trips they have made (De Vos and Witlox 2017). It has been found that travel satisfaction can be affected by travel mode (e.g., De Vos et al. 2016; Singleton 2019; Waygood et al. 2019), travel duration (e.g., Higgins et al. 2018; Morris and Guerra 2015), congestion levels (Higgins et al. 2018; Smith 2017), travel attitudes (e.g., St-Louis et al. 2014; Ye \& Titheridge 2017), the built environment (Mouratidis et al. 2019; Ye and Titheridge 2017), trip companionship (De Vos 2019; Zhu and Fan 2018; van den Berg et al. 2020), etc. However, the possible reverse effect of travel satisfaction on travel behaviour has not received much attention, although it is likely that choices are affected by how pleasant or unpleasant previous activities have been perceived. The retrospective evaluation of past episodes can affect the prospective choice of an alternative since people seek to increase their happiness by choosing an activity that maximises remembered pleasure (Kahneman et al. 1997; Kahneman and Krueger 2006). Alternatively, since people tend to avoid a loss more than acquiring a gain (i.e., loss aversion (Tversky and Kahneman, 1991)), people may avoid behaviour that previously has been experienced negatively. Studies that have analysed the effect of travel satisfaction on travel mode choice are rather fragmented. In a relatively old study, Reibstein et al. (1980) found that overall satisfaction with bus trips positively affects the frequency of bus use. Abou-Zeid and Ben-Akiva (2012) and Abou-Zeid et al. (2012) discovered that lower car satisfaction and higher PT satisfaction due to a temporary free PT pass made a switch from car to PT more likely. In a qualitative study, Beirão and Cabral (2007) found that the perceived service performance of car and PT trips has an important effect on choosing the respective mode. Domarchi et al. (2008) and Steg (2005) found that car use is positively influenced by the emotional and affective appraisal of the car. Using the same data as this study, De Vos et al. (2020) observed that satisfaction with the flexibility and offer of the PT service positively 
affects PT frequency. Similarly, Le et al. (2020) found that satisfaction with PT operations (e.g., travel/wait time reliability, service frequency) has a positive effect on PT frequency.

Besides behaviour itself, travel satisfaction may also affect elements influencing behaviour, such as the desire and intention to perform a certain behaviour and attitudes towards a certain behaviour. Carrus et al. (2008) found that positive anticipated emotions of travelling by PT have a positive effect on the desire to use PT instead of the car. A similar effect - of satisfaction with PT use on the desire to use PT-was found by De Vos et al. (2020). Lai and Chen (2011) found that the intention to use PT is positively affected by satisfaction with PT, while Carrus et al. (2008) found that anticipated emotions of travelling by PT (in the two weeks after measurement) affect the intention to use PT instead of the car. Finally, De Vos et al. (2019) found positive effects of the evaluation of walking and cycling trips on attitudes towards the respective modes.

Satisfaction with infrequent or irregular use of a particular travel mode is unlikely to affect future mode choice. However, repeated satisfying trips with a specific mode may result in a greater likelihood that the same mode will be chosen for a future trip. This positive reinforcement may generate scripted choice and habitual mode use. As a result, it may especially be the frequency of (dis)satisfying trips with a specific mode-rather than satisfaction with one or a limited number of trips using that mode-that affects how often that mode will be chosen for future trips. In this study we will consequently analyse how the current PT trip frequency, satisfaction with the PT service, and the frequency of (dis) satisfying PT trips influence the intention to use PT in later life stages in the case of Canadian University students. In doing so, this study provides new insights into how satisfaction with travel influences (future) travel behaviour, and how prior travel behaviour influences (intended) later behaviour.

\section{Data}

In this study, we use data from a 2013 survey conducted in Quebec, Canada, focusing on different aspects of PT. PT services in Quebec can-at least in North American termsbe regarded as relatively good. The service network covers an extensive area (comprising a bus network of $870 \mathrm{~km}$ in 2013, including $60 \mathrm{~km}$ of reserved lanes), the service frequency is relatively high (especially during peak hours and for the "Metrobus" (i.e., under $10 \mathrm{~min}$ )), and the buses are fairly new, clean, and well maintained. In 2011, PT was used for $9.2 \%$ of all trips in the Quebec Metropolitan Area, whereas cars were used for $78.9 \%$ of trips, while non-motorised modes accounted for $10.9 \%$ of trips. In $2010,38.1 \%$ of the Laval University students used PT to travel to campus, $26.4 \%$ used a car, and $35.1 \%$ walked or cycled ( $0.4 \%$ of the students did not report a main travel mode) (Barla et al. 2015).

In June 2013, all 20,125 students registered for the 2013 summer semester at Laval University (Canada), received an email inviting them to participate in an online survey on travel behaviour, with a focus on PT. In order to reduce possible sampling bias (such as PT users being more inclined to participate than non-PT users), the invitation was general in nature, indicating that the survey would ask for information on their use of, attitudes towards and satisfaction with various travel modes, although questions about PT were overrepresented in the survey. A total of 984 respondents completed the survey (response rate $=4.9 \%$ ), of which a small number were removed for some of the analyses due to missing data. The relatively low response rate could be due to the survey being conducted during the summer semester (a period in which students may be less inclined to check their 
academic email account), and the absence of a reward for survey completion. Although the collected data can be considered as relatively old, it does contain much richer information regarding PT frequency, satisfaction, attitudes and future intended use compared to other data sets commonly used in travel behaviour research.

The survey sample was composed of a higher proportion of women $(68.3 \%)$, students older than 24 (43.2\%), and full-time students (88.7\% of the students) than the general student population (Laval University 2013). Slightly less than half of the respondents owned a car $(47.2 \%)$ or had a PT pass (46.6\%). Most respondents $(54.3 \%)$ lived in an urban neighbourhood (i.e., city centre within first ring of Quebec), 39.7\% lived in a suburban neighbourhood (i.e., low-density neighbourhoods outside city centre), while only a small proportion $(6.0 \%)$ lived in a rural area (i.e., peripheral area within the metropolitan region) (Table 1). Since the main goal of this study is to achieve an analytical representation of relationships among multiple variables and not a descriptive analysis of the (student) population, it is important to have a large and sufficiently diverse sample rather than a representative sample (see, e.g., Groves 1989). Although our sample may not be fully representative of the students at Laval University, it is relatively large in size, which makes it possible to estimate specific relationships with ample confidence. For more information regarding the recruitment of participants and sample characteristics, see De Vos et al. (2020).

Among other questions, the survey asked respondents about their current frequency of PT use (on a Likert scale from 1 (Never) to 5 (Most of the time)), how satisfied they were with different aspects of PT (i.e., reliability, flexibility, duration, comfort, costs, offer and safety on a scale from 1 (Very dissatisfied) to 5 (Very satisfied)), and whether or not they intended to use PT in later life stages (i.e., as a young adult without child(ren), as an adult with child(ren), and when they are retired). Since the internal consistency (i.e., the average correlation) of the seven variables used to measure satisfaction with aspects of PT was good (Cronbach's alpha is 0.75), we created one variable representing satisfaction with PT by averaging the scores of the seven measures. ${ }^{1}$ An average score below 3 was categorised as 'low satisfaction', an average score from 3 to (less than) 4 was classified as 'medium satisfaction', while an average score of 4 or higher was labelled as 'high satisfaction'. Most previous studies (described in Sect. 2) have used cross-sectional data or-those focusing on the effects of a (temporary) context change (such as a free PT pass) on travel habits-a two- or three-wave survey approach. However, the latter studies mostly had a limited time span (i.e., ranging from one week to one year after an intervention) and did not take into account travel satisfaction. Since we asked respondents to provide information regarding their PT intentions in later life stages, the used data can be regarded as quasi-longitudinal, and can therefore provide valuable insights into how the frequency of mode use and travel satisfaction influence the intended use of that mode in later life. Despite intention being a strong explanatory factor of behaviour (as posited in the TPB), we do acknowledge that due to a possible intention-behaviour gap (whereby behaviour is not an outcome of prior

\footnotetext{
1 The constructed variable is technically not a latent variable since the original variables received an equal weighting by averaging them. In contrast, the influence of original variables on a latent variable (such as a factor resulting from a factor analysis) depends on the mutual association (e.g., represented by factor loadings). Since the main goal of a factor analysis is to identify underlying structures of a set of heterogeneous variables, performing a factor analysis on seven variables representing the same construct (as proven by the Cronbach's alpha value) is theoretically not valuable. The option of a factor analysis was explored, but the possible one- and two-factor solutions, however, did not result in strong/clear factors with high factor loadings (i.e., factor loadings $>0.75$ ).
} 
Table 1 Socio-demographics characteristics of respondents $(n=984)$

\begin{tabular}{|c|c|c|}
\hline Sample characteristic & Number & Percentage \\
\hline \multicolumn{3}{|l|}{ Gender } \\
\hline Women & 626 & 68.3 \\
\hline Men & 290 & 31.7 \\
\hline \multicolumn{3}{|l|}{ Age group } \\
\hline $18-20$ & 85 & 9.3 \\
\hline $21-24$ & 434 & 47.5 \\
\hline $25-34$ & 303 & 33.2 \\
\hline $35+$ & 92 & 10.0 \\
\hline \multicolumn{3}{|l|}{ Employment status $^{1}$} \\
\hline Full-time worker & 96 & 9.8 \\
\hline Part-time worker & 180 & 18.3 \\
\hline Full-time student & 777 & 79.0 \\
\hline Part-time student & 99 & 10.1 \\
\hline Unemployed & 10 & 1.0 \\
\hline \multicolumn{3}{|l|}{ Household Income } \\
\hline$<20,000 \mathrm{CAD}^{2}$ & 379 & 42.3 \\
\hline $20-45,000 \mathrm{CAD}$ & 202 & 22.5 \\
\hline $45,000+\mathrm{CAD}$ & 316 & 35.2 \\
\hline \multicolumn{3}{|l|}{ Car access level } \\
\hline No access & 157 & 17.1 \\
\hline Occasionally & 171 & 18.7 \\
\hline Often & 156 & 17.0 \\
\hline Owner & 432 & 47.2 \\
\hline \multicolumn{3}{|l|}{ Bus pass } \\
\hline No & 487 & 53.4 \\
\hline Yes & 425 & 46.6 \\
\hline \multicolumn{3}{|c|}{ Residential built environment } \\
\hline Urban & 495 & 54.3 \\
\hline Suburban & 362 & 39.7 \\
\hline Rural & 55 & 6.0 \\
\hline
\end{tabular}

${ }^{1}$ Since being a (part-time or full-time) student can be combined with a part-time or full-time job, the sum of percentages of the employment status is higher than $100 \%$. A substantial share of respondents (11.0\%) did not register as student, probably since the survey was conducted during the summer semester and last-year students already finished classes and/or already started working

${ }^{2} 1$ Canadian Dollar (CAD) is approximately 0.75 US Dollar, 0.58 UK Pound, and 0.65 Euro

intentions (Sheeran 2002)), future PT frequency may not fully correlate with respondents' current intentions.

Figure 1 shows that most respondents were frequent PT users. Only $12.4 \%$ of the respondents never used PT, while 52.6\% used PT regularly or mostly. ${ }^{2}$ Almost half of the

\footnotetext{
${ }^{2}$ Since the group of respondents never using PT is small, respondents never or rarely using PT are grouped for further analysis.
} 


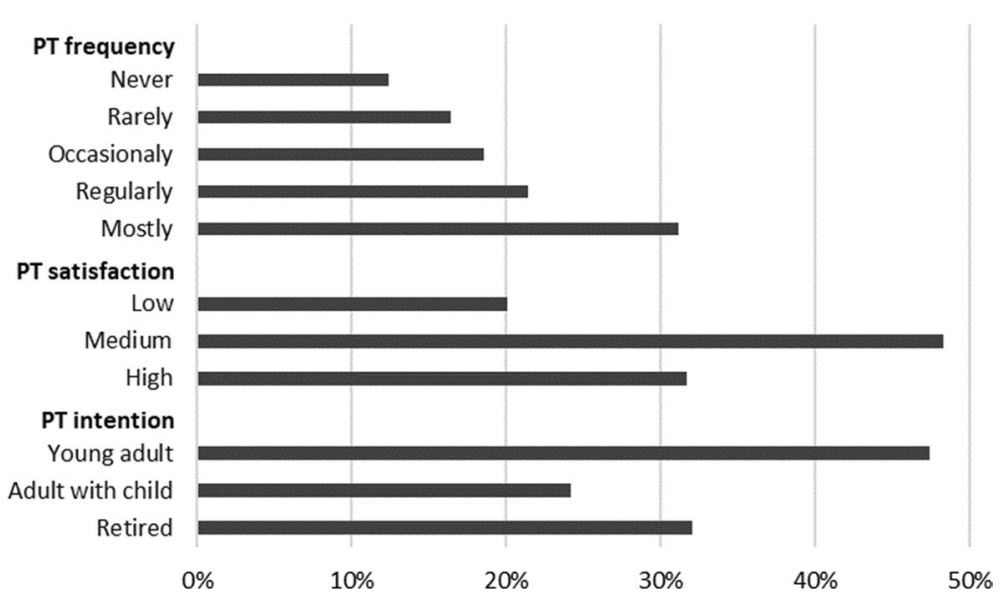

Fig. 1 PT frequency, PT satisfaction and PT intention in later life

respondents (48.3\%) were moderately satisfied with PT, while $20.1 \%$ were dissatisfied and $31.7 \%$ were clearly satisfied. Almost half of the respondents $(47.4 \%)$ indicated that they intend to use PT as a young adult without child(ren). However, considerably fewer of them (24.2\%) intended to use PT when they would have child(ren), while $32.1 \%$ of the respondents intended to use PT when retired.

\section{Results}

Pearson chi-square tests indicate that both PT frequency and PT satisfaction are significantly related with the intention to use PT in later life stages. Respondents who infrequently travelled by PT (i.e., occasionally or never) generally did not intend to use PT in later life stages. A higher proportion of those who already travelled regularly or mostly by PT intended to continue using PT in later life, and the majority intended to use PT as a young adult without child(ren) (Table 2). Similar results were found for PT satisfaction. Most respondents with a low PT satisfaction score did not intend to use PT in later life. Future intentions to use PT are clearly stronger for those with medium or high levels of PT satisfaction, although the intention to use PT only dominates for those with high levels of PT satisfaction and PT intention as a young, childless adult (Table 3).

In a second stage of analysis, we carried out two-way ANOVAs, in order to see whether there were any interaction effects between PT frequency and PT satisfaction. The intention to use PT as a young adult without child(ren) is significantly affected by the current PT use. A high current PT frequency results in a greater likelihood of the respondent intending to use PT as a young adult. The differences in intentions according to PT satisfaction are insignificant. No interaction effects were found for the intention to use PT as a young adult (Fig. 2). Current PT use also has a significant effect on the intention to use PT when respondents would become parents. The more frequent their current PT use, the greater the intention that they would use PT during this later life stage. PT satisfaction in itself does not have a significant influence on the intention to travel by PT when having child(ren), although interaction effects occur. Significant differences in intention according to PT satisfaction levels exist, but only for those mostly travelling by PT. For these frequent PT 


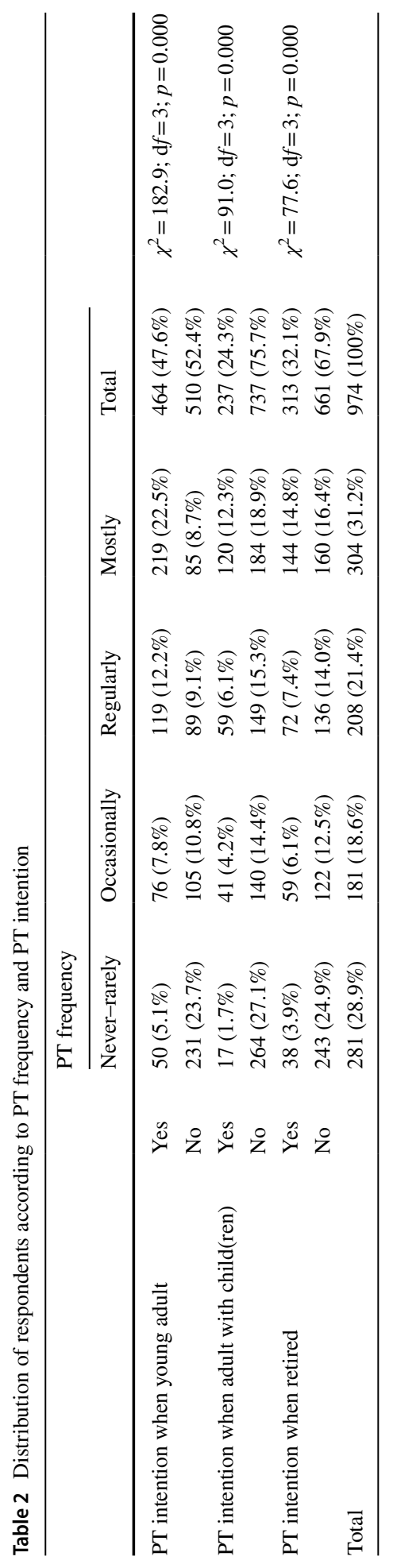




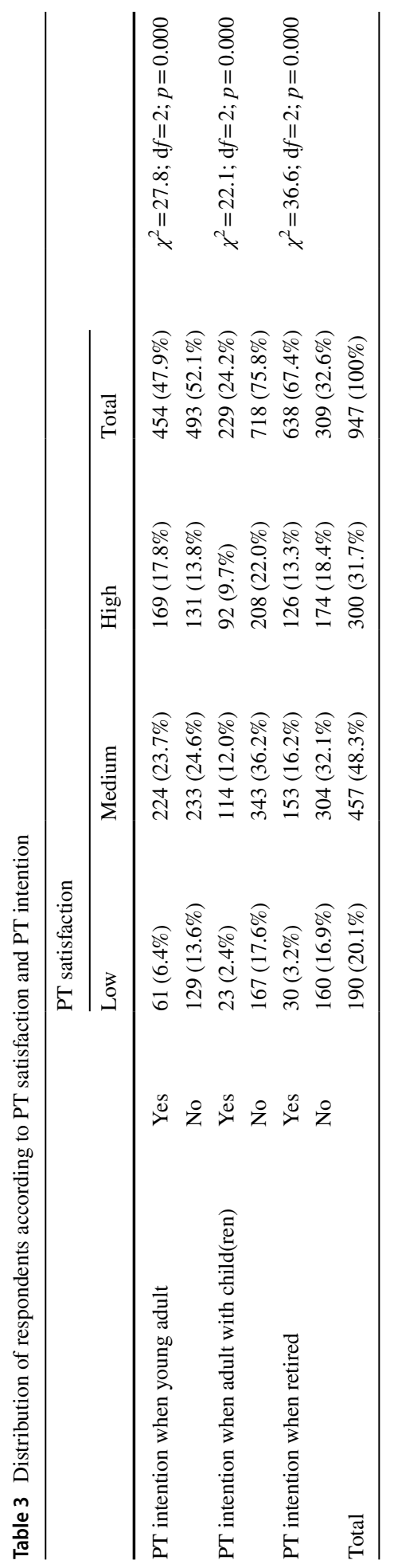




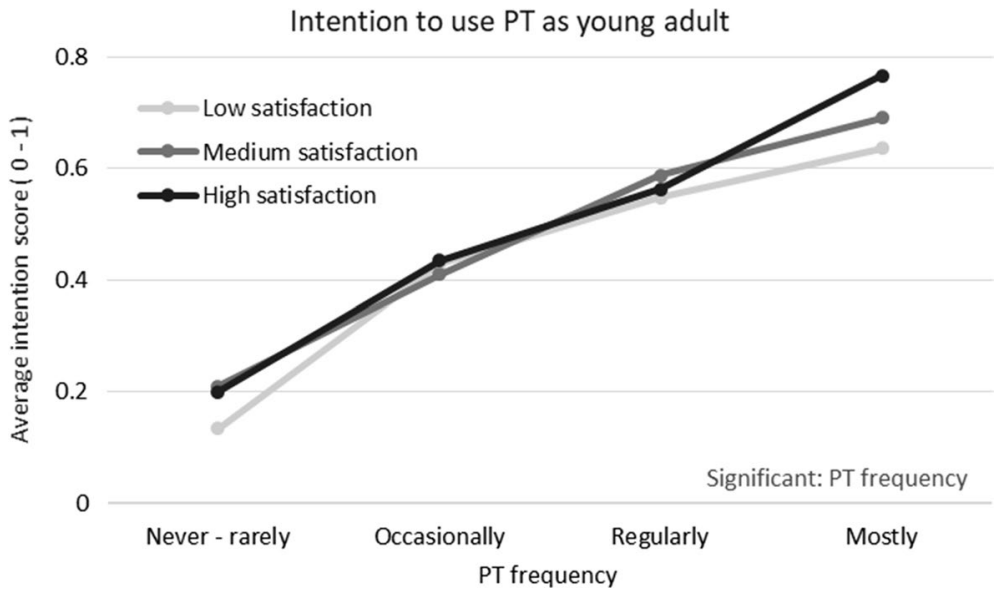

Fig. 2 Intention to use PT as a young adult according to PT frequency and PT satisfaction (effects statistically significant (at $p<0.05$ ) in a two-way analysis of variance are listed)

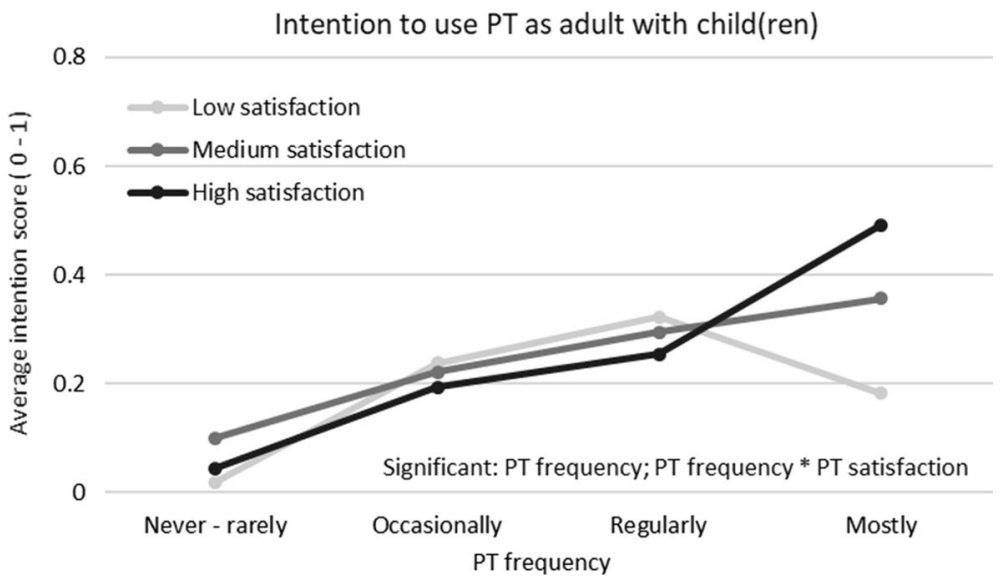

Fig. 3 Intention to use PT as an adult with child(ren) according to PT frequency and PT satisfaction (effects statistically significant (at $p<0.05)$ in a two-way analysis of variance are listed)

users, a higher level of satisfaction results in a greater likelihood of intending to use PT as an adult with child(ren) (Fig. 3). Finally, both PT satisfaction and PT frequency have a significant influence on the intention to use PT when retired, while no interaction effects were found. Frequently travelling by PT and being satisfied with PT is likely to translate into an intention to use PT when retired (Fig. 4).

In order to analyse which factors influence the intention to use PT in later life stages, we performed binary logistic regressions. For all three life stages, three models were estimated, one including PT frequency $(1=$ Never-rarely; $2=$ Occasionally; $3=$ Regularly; $4=$ Most of the time) as an independent variable, another including PT satisfaction ( $1=$ Low satisfaction; $2=$ Medium satisfaction; $3=$ High satisfaction) as an independent variable and a final one including PT frequency * PT satisfaction (min. $=1(1 * 1)$; $\max .=12(4 * 3))$ as an independent variable (Fig. 5). Three models (instead of combining 


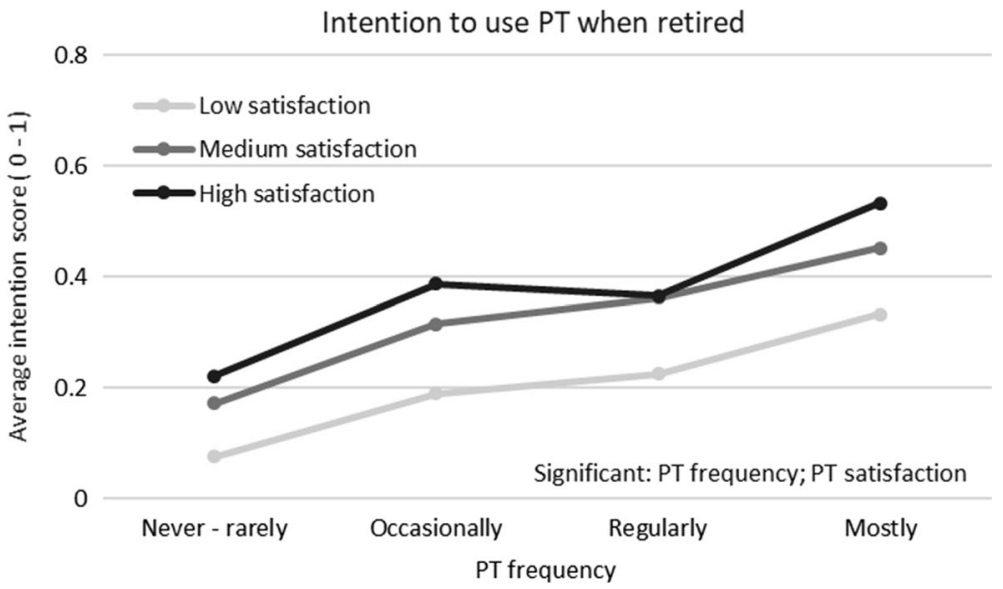

Fig. 4 Intention to use PT when retired according to PT frequency and PT satisfaction (effects statistically significant (at $p<0.05$ ) in a two-way analysis of variance are listed)

Fig. 5 Overview of the three different models

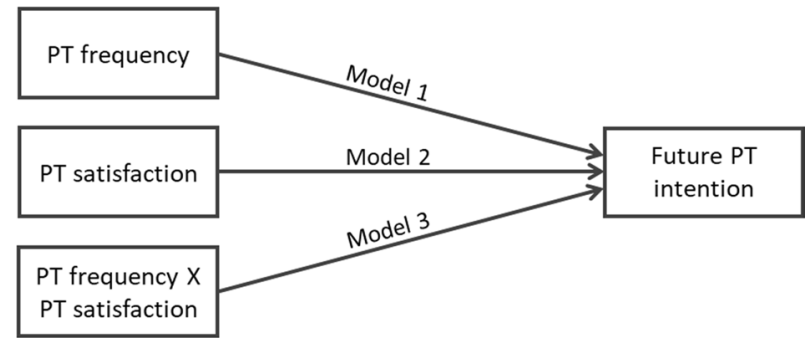

the above three independent variables in one or two models) were estimated for the following reasons. First, PT frequency * PT satisfaction is directly derived from PT frequency and PT satisfaction, therefore resulting in high levels of correlation between PT frequency * PT satisfaction and the other two variables (and problematic degrees of multicollinearity). Second, some degree of correlation between PT frequency and PT satisfaction exists, ${ }^{3}$ whereby the effect of PT frequency on PT intention is mediated by PT satisfaction (and vice versa), while our main goal is to analyse the independent (and interaction) effects of frequency and satisfaction on intention.

For all the regressions, the following socio-demographics were included: binary variables age $(0=18-24$ years; $1=25+$ years $)$, gender $(0=$ men; $1=$ women $)$, and car ownership $(0=$ not owning a car; $1=$ owning a car $)$, as well as categorical variables household income $(1=<20,000 \mathrm{CAD} ; 2=20,000-45,000 \mathrm{CAD} ; 3=45,000+\mathrm{CAD})$, and residential location $(1=$ urban; $2=$ suburban; $3=$ rural $)$. Initially we also included binary variable PT pass $(0=$ no PT pass; $1=\mathrm{PT}$ pass $)$, and categorical variable PT attitudes $(1=I$ absolutely

\footnotetext{
3 Based on a Spearman correlation analysis, we found that PT frequency and PT satisfaction are positively correlated with each other (at $\mathrm{p}<0.01)$. A crosstabulation and significant chi-square test $($ at $\mathrm{p}<0.01)$ show that respondents regularly or mostly using PT are often satisfied with PT, while infrequent PT users are often dissatisfied. This finding is in line with existing studies demonstrating a positive relationship between the use of PT and satisfaction with PT (e.g., Abenoza et al. 2017).
} 
Table 4 Binary logistic regressions for PT intention as a young adult without child(ren)

\begin{tabular}{|c|c|c|c|c|c|c|}
\hline & \multicolumn{2}{|l|}{ Model 1} & \multicolumn{2}{|l|}{ Model 2} & \multicolumn{2}{|l|}{ Model 3} \\
\hline & Coef. & $(\mathrm{OR})$ & Coef. & $(\mathrm{OR})$ & Coef. & $(\mathrm{OR})$ \\
\hline Constant & $-1.02 * * *$ & $(0.36)$ & -0.16 & $(0.86)$ & $-0.94 * * *$ & $(0.39)$ \\
\hline Age $(25+$ years $)$ & $0.29 *$ & $(1.34)$ & $0.36^{* *}$ & $(1.44)$ & $0.35 * *$ & $(1.43)$ \\
\hline Gender (women) & -0.08 & $(0.93)$ & -0.06 & $(0.94)$ & -0.02 & $(0.98)$ \\
\hline \multicolumn{7}{|l|}{ Income (ref. $=<20,000 \mathrm{CAD})$} \\
\hline $20-45,000 \mathrm{CAD}$ & 0.10 & $(1.11)$ & 0.06 & $(1.06)$ & 0.08 & $(1.08)$ \\
\hline $45,000+\mathrm{CAD}$ & -0.02 & $(0.98)$ & -0.09 & $(0.91)$ & -0.07 & $(0.93)$ \\
\hline \multicolumn{7}{|l|}{ Residential location (ref. = urban) } \\
\hline Suburban & $-0.80^{*}$ & $(0.45)$ & $-1.32 * * *$ & $(0.27)$ & $-1.12 * *$ & $(0.33)$ \\
\hline Rural & -0.03 & $(0.97)$ & -0.01 & $(0.99)$ & 0.02 & $(1.02)$ \\
\hline Car ownership & $-0.50 * * *$ & $(0.61)$ & $-1.03 * * *$ & $(0.36)$ & $-0.67 * * *$ & $(0.51)$ \\
\hline \multicolumn{7}{|l|}{ PT freq. (ref. = Never-rarely) } \\
\hline Occasionally & $0.88 * * *$ & $(2.41)$ & & & & \\
\hline Regularly & $1.48 * * *$ & $(4.40)$ & & & & \\
\hline Mostly & $1.99 * * *$ & $(7.31)$ & & & & \\
\hline \multicolumn{7}{|l|}{ PT satisfaction (ref. = low) } \\
\hline Medium & & & $0.60 * * *$ & $(1.81)$ & & \\
\hline High & & & $0.78 * * *$ & $(2.19)$ & & \\
\hline PT frequency X PT satisfaction & & & & & $0.19 * * *$ & $(1.22)$ \\
\hline$n$ & 884 & & 880 & & 874 & \\
\hline $\mathrm{Chi}^{2}$ (Omnibus tests of model coefficients) & 180.06 & & 103.04 & & 159.93 & \\
\hline Sig & 0.000 & & 0.000 & & 0.000 & \\
\hline-2 Log likelihood & 1044.54 & & 1116.25 & & 1051.14 & \\
\hline Nagelkerke $R$ square & 0.25 & & 0.15 & & 0.22 & \\
\hline
\end{tabular}

$\mathrm{OR}=$ odds ratio; $* p<0.05 ; * * p<0.01 ; * * * p<0.001$

dislike PT; $2=I$ dislike $P T ; 3=$ neutral $; 4=I$ like $P T ; 5=I$ really like $P T$ ). However, since PT pass is highly correlated with PT frequency and PT attitudes is highly correlated with PT satisfaction, these two variables were excluded from the regression analyses.

Table 4 reveals that being younger than 25 years, living in a suburban neighbourhood and owning a car negatively affects the intention to use PT as a young, childless adult. Models 1, 2, and 3 respectively show that PT frequency, PT satisfaction, and PT frequency * PT satisfaction have a strong positive effect on the intention to use PT as young adult. The Nagelkerke R square values indicate that model 1 (including PT frequency) explains more of the variance in PT intention compared to model 3 (including PT frequency * PT satisfaction), and especially compared to model 2 (including PT satisfaction). The chisquare values also indicate that model 1 is the best model, followed by model 3 and model 2, respectively. This finding is in line with the two-way ANOVA shown in Fig. 2, which indicates that PT frequency has a strong positive effect on the intention to use PT as a young adult.

Table 5 shows that the intention to use PT when respondents would have child(ren) is positively affected by being older than 24 years, being male, living in an urban neighbourhood, and not owning a car (although residential location and car ownership do not 
Table 5 Binary logistic regressions for PT intention as an adult with child(ren)

\begin{tabular}{|c|c|c|c|c|c|c|}
\hline & \multicolumn{2}{|l|}{ Model 1} & \multicolumn{2}{|l|}{ Model 2} & \multicolumn{2}{|l|}{ Model 3} \\
\hline & Coef. & $(\mathrm{OR})$ & Coef. & $(\mathrm{OR})$ & Coef. & $(\mathrm{OR})$ \\
\hline Constant & $-2.13 * * *$ & $(0.12)$ & $-1.28 * * *$ & $(0.28)$ & $-1.83 * * *$ & $(0.16)$ \\
\hline Age $(25+$ years $)$ & $0.44 * *$ & $(1.55)$ & $0.51 * * *$ & $(1.67)$ & $0.49 * * *$ & $(1.63)$ \\
\hline Gender (women) & $-0.36 * *$ & $(0.70)$ & $-0.36^{* *}$ & $(0.70)$ & $-0.31^{*}$ & $(0.73)$ \\
\hline \multicolumn{7}{|l|}{ Income (ref. $=<20,000 \mathrm{CAD}$ ) } \\
\hline $20-45,000 \mathrm{CAD}$ & -0.15 & $(0.86)$ & -0.17 & $(0.85)$ & -0.18 & $(0.84)$ \\
\hline $45,000+\mathrm{CAD}$ & -0.06 & $(0.95)$ & -0.09 & $(0.92)$ & -0.10 & $(0.90)$ \\
\hline \multicolumn{7}{|l|}{ Residential location (ref. = urban) } \\
\hline Suburban & -0.72 & $(0.49)$ & $-1.31^{* *}$ & $(0.27)$ & $-1.12 *$ & $(0.33)$ \\
\hline Rural & -0.29 & $(0.75)$ & -0.26 & $(0.77)$ & -0.26 & $(0.77)$ \\
\hline Car ownership & -0.27 & $(0.77)$ & $-0.77 * * *$ & $(0.46)$ & $-0.40 * *$ & $(0.67)$ \\
\hline \multicolumn{7}{|l|}{ PT freq. (ref. $=$ Never-rarely) } \\
\hline Occasionally & $1.20 * * *$ & $(3.31)$ & & & & \\
\hline Regularly & $1.55^{* * * *}$ & $(4.73)$ & & & & \\
\hline Mostly & $1.99^{* * *}$ & $(7.32)$ & & & & \\
\hline \multicolumn{7}{|l|}{ PT satisfaction (ref. = low) } \\
\hline Medium & & & $0.79 * * *$ & $(2.20)$ & & \\
\hline High & & & $0.96 * * *$ & $(2.61)$ & & \\
\hline PT frequency X PT satisfaction & & & & & $0.18^{* * *}$ & $(1.19)$ \\
\hline$n$ & 884 & & 880 & & 874 & \\
\hline $\mathrm{Chi}^{2}$ (Omnibus tests of model coefficients) & 110.59 & & 71.09 & & 104.25 & \\
\hline Sig & 0.000 & & 0.000 & & 0.000 & \\
\hline-2 Log likelihood & 883.62 & & 920.81 & & 881.99 & \\
\hline Nagelkerke R square & 0.17 & & 0.12 & & 0.17 & \\
\hline
\end{tabular}

$\mathrm{OR}=$ odds ratio; $* p<0.05 ; * * p<0.01 ; * * * p<0.001$

have significant effects in model 1). Similar to PT intention as a young adult, the intention to use PT when respondents become parents is significantly and positively affected by PT frequency, PT satisfaction and PT frequency * PT satisfaction. The Nagelkerke $\mathrm{R}$ square values are somewhat lower than those shown in Table 4, indicating that the elements included in the models (such as PT frequency and PT satisfaction) can only explain the intention to use PT when having child(ren) to a limited extent. This may suggest that a sizeable proportion of people may find that PT is not suitable or sufficiently developed for escorting children to school and other activities, and that the focus of PT (in Quebec) is getting people to and from work. Models 1 and 3-including respectively $\mathrm{PT}$ frequency and $\mathrm{PT}$ frequency * $\mathrm{PT}$ satisfaction-can be considered the best models as they have the highest chi-square values and Nagelkerke $\mathrm{R}$ square values. This is in line with the two-way ANOVA shown in Fig. 3, indicating effects of PT frequency and interaction effects (of PT frequency and PT satisfaction) on the intention to use PT as an adult with child(ren).

Table 6 indicates that the intention to use PT when retired is positively impacted by being male, living in an urban neighbourhood, and not owning a car. Similar to the intention to use PT as an adult both with and without child(ren), PT frequency, PT satisfaction 
Table 6 Binary logistic regressions for PT intention when retired

\begin{tabular}{|c|c|c|c|c|c|c|}
\hline & \multicolumn{2}{|l|}{ Model 1} & \multicolumn{2}{|l|}{ Model 2} & \multicolumn{2}{|l|}{ Model 3} \\
\hline & Coef. & $(\mathrm{OR})$ & Coef. & $(\mathrm{OR})$ & Coef. & $(\mathrm{OR})$ \\
\hline Constant & $-0.98 * * *$ & $(0.38)$ & $-0.83 * * *$ & $(0.44)$ & $-0.97 * * *$ & $(0.38)$ \\
\hline Age $(25+$ years $)$ & 0.14 & $(1.15)$ & $0.26^{*}$ & $(1.30)$ & 0.19 & $(1.21)$ \\
\hline Gender (female) & $-0.34 * *$ & $(0.71)$ & $-0.36 * *$ & $(0.70)$ & $-0.31 *$ & $(0.73)$ \\
\hline \multicolumn{7}{|l|}{ Income (ref. $=<20,000$ CAD) } \\
\hline $20-45,000 \mathrm{CAD}$ & -0.19 & $(0.83)$ & -0.16 & $(0.86)$ & -0.20 & $(0.82)$ \\
\hline $45,000+\mathrm{CAD}$ & -0.14 & $(0.87)$ & -0.15 & $(0.86)$ & -0.17 & $(0.84)$ \\
\hline \multicolumn{7}{|l|}{ Residential location (ref. = urban) } \\
\hline Suburban & -0.31 & $(0.74)$ & -0.44 & $(0.64)$ & -0.32 & $(0.73)$ \\
\hline Rural & $-0.35 * *$ & $(0.71)$ & $-0.31 *$ & $(0.74)$ & $-0.32 *$ & $(0.73)$ \\
\hline Car ownership & $-0.45^{* *}$ & $(0.64)$ & $-0.82 * * *$ & $(0.44)$ & $-0.51 * * *$ & $(0.60)$ \\
\hline \multicolumn{7}{|l|}{ PT freq. (ref. $=$ Never-rarely) } \\
\hline Occasionally & $0.86 * * *$ & $(2.37)$ & & & & \\
\hline Regularly & $0.88 * * *$ & $(2.42)$ & & & & \\
\hline Mostly & $1.37 * * *$ & $(3.95)$ & & & & \\
\hline \multicolumn{7}{|l|}{ PT satisfaction $($ ref. $=$ low) } \\
\hline Medium & & & $0.89 * * *$ & $(2.44)$ & & \\
\hline High & & & $1.14 * * *$ & $(3.12)$ & & \\
\hline PT frequency X PT satisfaction & & & & & $0.14 * * *$ & $(1.15)$ \\
\hline$n$ & 884 & & 880 & & 874 & \\
\hline Chi2 (Omnibus tests of model coefficients) & 94.60 & & 83.37 & & 93.19 & \\
\hline Sig & 0.000 & & 0.000 & & 0.000 & \\
\hline-2 Log likelihood & 1025.61 & & 1037.82 & & 1018.97 & \\
\hline Nagelkerke $R$ square & 0.14 & & 0.13 & & 0.14 & \\
\hline
\end{tabular}

$\mathrm{OR}=$ odds ratio $; * p<0.05 ; * * p<0.01 ; * * * p<0.001$

and PT frequency * PT satisfaction positively influence the intention to use PT when retired. The chi-square values and Nagelkerke R square values in model 1 and model 3 are considerably lower than those in Tables 4 and 5. This suggests that a person's current PT frequency has a stronger effect on their intention to use PT as an adult with and without (resident) child(ren) than on their intention to use PT when retired, indicating that the effect of prior behaviour on later (intended) behaviour may diminish over time. The chi-square value and Nagelkerke $\mathrm{R}$ square value in model 2 are similar to those in models 1 and 3 and similar to those in models 2 shown in Tables 4 and 5, indicating that PT satisfaction plays a relatively important role in the intention to use PT when retired. In comparison with the intention to use PT when respondents would have child(ren), where practical considerations may outweigh preferences for specific modes, the intention to use PT when retired may be influenced more by satisfaction with PT trips. Another consideration that they may have is that when retired, their time restrictions may not be as great, and using PT is less expensive than owning and operating a car. This finding is in line with the two-way ANOVAs. The two-way ANOVA analysing PT intention when retired (Fig. 4) is the only one that shows significant effects of PT satisfaction on PT intention. 


\section{Discussion and conclusion}

Results from this study indicate that almost half of the respondents (i.e., students from Laval University, Canada) have the intention to use PT when they are young adults without child(ren). The share of respondents intending to use PT as an adult with (resident) child(ren) is considerably lower (around one in four), while approximately one third of the respondents intend to use PT when they are retired. The results of the chi-square tests, twoway ANOVAs and binary logistic regressions show that PT frequency, PT satisfaction and the interaction between PT frequency and PT satisfaction have positive effects on the intention to use PT in later life, although differences exist between the three future life stages. The intention to use PT as a childless adult is mainly affected by the current frequency of PT use; university students who already use PT regularly or often intend to continue doing so in the next stage of their lives. The intention to use PT as an adult with child(ren) is also clearly affected by the current PT frequency, although interaction effects are also strong. Satisfaction with PT has a strong effect on the intention to use PT in this life stage, but mainly for those who already use PT a lot. The intention to use PT when retired is strongly affected by both PT frequency and PT satisfaction; students who frequently use PT and have high levels of PT satisfaction intend to use PT when they are retired.

Overall, the results of this study indicate that frequent satisfying PT trips can positively influence future PT use. This suggests that travel satisfaction can play an important role in the formation of habitual mode use, and that satisfying types of trips (e.g., using a specific travel mode) are likely to be repeated in the future. It may be possible that prior behaviour mainly affects future (intended) behaviour for those with limited (expected) travel options, while satisfaction has a greater influence on future behaviour for those with ample options. Since PT users are often regarded as captive travellers (i.e., forced to use a particular mode due to limited available travel options (e.g., Beimborn et al. 2003)), this could partly explain why the effect of PT frequency on PT intention was found to be stronger than the effect of PT satisfaction on PT intention. A previous study analysing travel behaviour of students of Laval University, indicated that many students aspired to purchase cars once they have completed their studies, and they were only using PT because they felt they had to (Bojanowski et al. 2015). For other modes, where the choice is mostly based more on preferences rather than necessity and where travel satisfaction is generally higher (De Vos 2018), it may be possible that future intended use is more affected by satisfaction levels than by current frequency. As a result, we recommend future studies to analyse the effect of travel satisfaction on travel behaviour for various travel modes.

In order to increase PT ridership — or at least people's intention to use PT in later stages of life-policy makers should try to increase the frequency of use among children and young adults as this will result in them being more likely to want to use PT in later life stages. This could be done, for example, by giving secondary school and university students free PT passes. Previous studies have indicated that offering free PT passes will result in a higher level of PT ridership (Abou-Zeid and Ben-Akiva 2012; Bamberg et al. 2003a; Fujii and Kitamura 2003; Thøgersen and Møller 2008). The intention to use PT in later life can be further strengthened by trying to improve PT satisfaction levels. This could be done by improving PT service factors that have an important influence on PT passengers' satisfaction, such as cleanliness, comfort, safety, punctuality, frequency, travel time, waiting conditions, accessibility and on-board information (de Oña et al. 2013; dell'Olio et al. 2011; van Lierop et al. 2018). Furthermore, policy makers should try to make it more convenient for parents to travel by PT with their child(ren) - e.g., by improving buggy access, 
making trip chaining easier (e.g., by increasing PT coverage and service frequency), having (better) service on the weekend, allowing children to travel free with parents (during off-peak hours), and providing better service to destinations that are not work centres-in order to increase the likelihood that people will want to use PT when they have child(ren).

The data used in this study can be regarded as quasi-longitudinal (because respondents were asked to provide information about future intentions). Although this has proven to be valuable for exploring future PT intentions, we cannot know whether people's intentions will be converted into actual behaviour. In order to find out, it would be necessary to use true longitudinal data. Future studies should therefore try to collect longitudinal data to capture the effect of prior behaviour and travel satisfaction on future travel behaviour. Unfortunately, longitudinal data (especially over long periods) are scarce, as they are expensive and time consuming to collect. A longitudinal study that at least addressed the attitudinal side perspective of University students' travel behaviour did find that car attitudes affected the purchase and use of cars after graduation (Fujii 2007). Another study, using three-wave panel data in Germany, followed university students after they graduated and found that current habits could influence future behaviour post-graduation (BuschGeertsema and Lanzendorf 2017). However, these studies did not examine effects of satisfaction. A possible solution would be to include travel satisfaction questions in national household (travel) surveys, which are often conducted in multiple waves over longer periods. An alternative approach may be to retrospectively ask respondents about how they travelled during previous life stages (e.g., similar to mobility biography approaches which involve the reconstruction of major life stages (Müggenburg et al. 2015)). However, it is worth bearing in mind that responses (whether from quantitative surveys or qualitative interviews) might be subject to memory bias. Furthermore, this approach does not enable to analyse effects from travel satisfaction on travel behaviour, since retrospectively measuring aspects such as travel satisfaction (but also travel attitudes) could be regarded as unreliable.

Acknowledgements The authors would like to thank the two anonymous reviewers for their constructive comments and suggestions, making it possible to improve the quality of this paper. As well, the authors would like to thank Sebastien Pouliot who helped develop the original survey.

Author contribution JDV Study conception and design, literature search and review, analysis and interpretation of results, manuscript writing; E.O.D. W: Data collection, manuscript editing; L. L: Data collection; M. C: Manuscript editing. All authors read and approved the final manuscript.

\section{Declarations}

Conflict of interest On behalf of all authors, the corresponding author states that there is no conflict of interest.

Open Access This article is licensed under a Creative Commons Attribution 4.0 International License, which permits use, sharing, adaptation, distribution and reproduction in any medium or format, as long as you give appropriate credit to the original author(s) and the source, provide a link to the Creative Commons licence, and indicate if changes were made. The images or other third party material in this article are included in the article's Creative Commons licence, unless indicated otherwise in a credit line to the material. If material is not included in the article's Creative Commons licence and your intended use is not permitted by statutory regulation or exceeds the permitted use, you will need to obtain permission directly from the copyright holder. To view a copy of this licence, visit http://creativecommons.org/licenses/by/4.0/. 


\section{References}

Aarts, H., Verplanken, B., van Knippenberg, A.: Predicting behavior from actions in the past: repeated decision making or a matter of habit? J. Appl. Soc. Psychol. 28(15), 1355-1374 (1998)

Abenoza, R.F., Cats, O., Susilo, Y.O.: Travel satisfaction with public transport: determinants, user classes, regional disparities and their evolution. Transp. Res. Part A 95, 64-84 (2017)

Abou-Zeid, M., Ben-Akiva, M.: Travel mode switching: comparison of findings from two public transportation experiments. Transp. Policy 24, 48-59 (2012)

Abou-Zeid, M., Witter, R., Bierlaire, M., Kaufmann, V., Ben-Akiva, M.: Happiness and travel mode switching: findings from a Swiss public transportation experiment. Transp. Policy 19(1), 93-104 (2012)

Ajzen, I.: The theory of planned behavior. Organ. Behav. Hum. Decis. Process. 50(2), 179-211 (1991)

Bagley, M.N., Mokhtarian, P.L.: The impact of residential neighborhood type on travel behavior: a structural equations modeling approach. Ann. Reg. Sci. 36(2), 279-297 (2002)

Bamberg, S., Ajzen, I., Schmidt, P.: Choice of travel mode in the theory of planned behavior: the roles of past behavior, habit, and reasoned action. Basic Appl. Soc. Psychol. 25(3), 175-187 (2003a)

Bamberg, S., Rölle, D., Weber, C.: Does habitual car use not lead to more resistance to change of travel mode? Transportation 30, 97-108 (2003b)

Barla, P., Lapierre, N., Daziano, R.A., Herrmann, M.: Reducing automobile dependency on campus using transport demand management: a case study for Quebec City. Can. Public Policy 41(1), 86-96 (2015)

Beimborn, E., Greenwald, M., Jin, X.: Accessibility, connectivity, and captivity: impacts on transit choice. Transp. Res. Rec. 1835, 1-9 (2003)

Beirão, G., Cabral, J.A.S.: Understanding attitudes towards public transport and private car: a qualitative study. Transp. Policy 14(6), 478-489 (2007)

Bojanowski, A., Craig-St-Louis, C., Falardeau, D.: Comportements en matière de transport à l'Université Laval : étudiés, représentés dans l'espace et inspirant l'élaboration de stratégies informatives efficaces. Université Laval, Québec (2015)

Busch-Geertsema, A., Lanzendorf, M.: From university to work life - Jumping behind the wheel? Explaining mode change of students making the transition to professional life. Transp. Res. Part A 106, 181196 (2017)

Cao, X., Mokhtarian, P.L., Handy, S.L.: Examining the impacts of residential self-selection on travel behaviour: a focus on empirical findings. Transp. Rev. 29(3), 359-395 (2009)

Carrus, G., Passafaro, P., Bonnes, M.: Emotions, habits and rational choices in ecological behaviours: the case of recycling and use of public transportation. J. Environ. Psychol. 28(1), 51-62 (2008)

Cervero, R., Kockelman, K.: Travel demand and the 3Ds: density, diversity and design. Transp. Res. Part D 2(3), 199-219 (1997)

de Oña, J., de Oña, R., Eboli, L., Mazzulla, G.: Perceived service quality in bus transit service: a structural equation approach. Transp. Policy 29, 219-226 (2013)

De Vos, J.: The influence of land use and mobility policy on travel behavior: a comparative case study of Flanders and the Netherlands. J. Transp. Land Use 8(1), 171-190 (2015)

De Vos, J.: Do people travel with their preferred travel mode? Analysing the extent of travel mode dissonance and its effect on travel satisfaction. Transp. Res. Part A 117, 261-274 (2018)

De Vos, J.: Analysing the effect of trip satisfaction on satisfaction with the leisure activity at the destination of the trip, in relationship with life satisfaction. Transportation 46(3), 623-645 (2019)

De Vos, J., Witlox, F.: Travel satisfaction revisited. On the pivotal role of travel satisfaction in conceptualising a travel behaviour process. Transp. Res. Part A 106, 364-373 (2017)

De Vos, J., Mokhtarian, P.L., Schwanen, T., Van Acker, V., Witlox, F.: Travel mode choice and travel satisfaction: bridging the gap between decision utility and experienced utility. Transportation 43(5), 771796 (2016)

De Vos, J., Schwanen, T., Van Acker, V., Witlox, F.: Do satisfying walking and cycling trips result in more future trips with active travel modes? An exploratory study. Int. J. Sustain. Transp. 13(3), 180-196 (2019)

De Vos, J., Waygood, E.O.D., Letarte, L.: Modeling the desire for using public transport. Travel Behav. Soc. 19, 90-98 (2020)

dell'Olio, L., Ibeas, A., Cecin, P.: The quality of service desired by public transport users. Transp. Policy 18, 217-227 (2011)

Domarchi, C., Tudela, A., González, A.: Effect of attitudes, habit and affective appraisal on mode choice: an application to university workers. Transportation 35(5), 585-599 (2008)

Ewing, R., Cervero, R.: Travel and the built environment: a synthesis. Transp. Res. Rec. 1780, 87-114 (2001) 
Ewing, R., Cervero, R.: Travel and the built environment. A meta-analysis. J. Am. Plan. Assoc. 76(3), 265294 (2010)

Frank, L.D., Pivo, G.: Impacts of mixed use and density on utilization of three modes of travel: singleoccupant vehicle, transit, and walking. Transp. Res. Rec. 1466, 44-52 (1994)

Fujii, S.: Communication with non-drivers for promoting long-term pro-environmental travel behaviour. Transp. Res. Part d: Transp. Environ. 12(2), 99-102 (2007)

Fujii, S., Kitamura, R.: What does a one-month free bus ticket do to habitual drivers? Transportation 30(1), 81-95 (2003)

Gardner, B.: Modelling motivation and habit in stable travel mode contexts. Transp. Res. Part F 12, 68-76 (2009)

Gärling, T., Axhausen, K.W.: Introduction: habitual travel choice. Transportation 30(1), 1-11 (2003)

Groves, R.M.: Survey Errors and Survey Costs. John Wiley and Sons, New York (1989)

Handy, S.L., Cao, X., Mokhtarian, P.L.: Correlation or causality between the built environment and travel behavior? Evidence from Northern California. Transp. Res. Part D 10(6), 427-444 (2005)

Heinen, E., Maat, K., van Wee, B.: The role of attitudes toward characteristics of bicycle commuting on the choice to cycle to work over various distances. Transp. Res. Part D 16(2), 102-109 (2011)

Higgins, C.D., Sweet, M.N., Kanaroglou, P.S.: All minutes are not equal: travel time and the effects of congestion on commute satisfaction in Canadian cities. Transportation 45(5), 1249-1268 (2018)

Kahneman, D., Krueger, A.B.: Developments in the measurement of subjective wellbeing. Journal of Economic Perspectives 20(1), 3-24 (2006)

Kahneman, D., Wakker, P.P., Sarin, R.: Back to Bentham? Explorations of experienced utility. Quart. J. Econ. 112(2), 375-405 (1997)

Kitamura, R., Mokhtarian, P.L., Laidet, L.: A micro-analysis of land use and travel in five neighborhoods in the San Francisco Bay Area. Transportation 24(2), 125-158 (1997)

Klöckner, C.A., Matthies, E.: How habits interfere with norm-directed behavior: a normative decisionmaking model for travel mode choice. J. Environ. Psychol. 24(3), 319-327 (2004)

Lai, W.-T., Chen, C.-F.: Behavioral intentions of public transit passengers - The roles of service quality, perceived value, satisfaction and involvement. Transp. Policy 18(2), 318-325 (2011)

Laval University, 2013. Profil de la population étudiante. Laval University, Quebec. Retrieved from https://www.reg.ulaval.ca/

Le, H.T.K., Carrel, A.L., Li, M.: How much dissatisfaction is too much for transit? Linking transit user satisfaction and loyalty using panel data. Travel Behaviour and Society 20, 144-154 (2020)

Morris, E.A., Guerra, E.: Are we there yet? Trip duration and mood during travel. Transp. Res. Part F 33, 38-47 (2015)

Mouratidis, K., Ettema, D., Næss, P.: Urban form, travel behavior, and travel satisfaction. Transp. Res. Part A 129, 306-320 (2019)

Müggenburg, H., Busch-Geertsema, A., Lanzendorf, M.: Mobility biographies: a review of achievements and challenges of the mobility biographies approach and a framework for further research. J. Transp. Geogr. 46, 151-163 (2015)

Reibstein, D.J., Lovelock, C.H., Dobson, R.P.: The direction of causality between perceptions, affect, and behavior: an application to travel behavior. J. Consum. Res. 6(4), 370-376 (1980)

Sheeran, P.: Intention-behavior relations: a conceptual and empirical review. Eur. Rev. Soc. Psychol. 12(1), 1-36 (2002)

Singleton, P.A.: Walking (and cycling) to well-being: modal and other determinants of subjective wellbeing during the commute. Travel Behaviour and Society 16, 249-261 (2019)

Smith, O.: Commute well-being differences by mode: evidence from Portland, Oregon, USA. J. Transp. Health 4, 246-254 (2017)

Steg, L.: Car use: lust and must. Instrumental, symbolic and affective motives for car use. Transportation Research Part A 39(2-3), 147-162 (2005)

St-Louis, E., Manaugh, K., van Lierop, D., El-Geneidy, A.: The happy commuter: a comparison of commuter satisfaction across modes. Transp. Res. Part F 26, 160-170 (2014)

Thøgersen, J.: Understanding repetitive travel mode choices in a stable context: a panel study approach. Transp. Res. Part A 40(8), 621-638 (2006)

Thøgersen, J., Møller, B.: Breaking car use habits: the effectiveness of a free one-month travelcard. Transportation 35, 329-345 (2008)

Triandis, H.C.: Interpersonal Behaviour. Brooks/Cole, Monterey (1977)

Tversky, A., Kahneman, D.: Loss aversion in riskless choice: A reference-dependent model. Q J Econ 106(4), 1039-1061 (1991) 
van den Berg, P., Waygood, E.O.D., van de Craats, I., Kemperman, A.: Factors affecting parental safety perception, satisfaction with school travel and mood in primary school children in the Netherlands. J. Transp. Health 16, 100837 (2020)

van Lierop, D., Badami, M.G., El-Geneidy, A.: What influences satisfaction and loyalty in public transport? A review of the literature. Transp. Rev. 38(1), 52-72 (2018)

Verplanken, B., Aarts, H., van Knippenberg, A.: Habit, information acquisition, and the process of making travel mode choices. Eur. J. Soc. Psychol. 27(5), 539-560 (1997)

Verplanken, B., Aarts, H., van Knippenberg, A., Moonen, A.: Habit versus planned behaviour: a field experiment. Br. J. Soc. Psychol. 37(1), 111-128 (1998)

Verplanken, B., Walker, I., Davis, A., Jurasek, M.: Context change and travel mode choice: combining the habit discontinuity and self-activation hypotheses. J. Environ. Psychol. 28(2), 121-127 (2008)

Walker, I., Thomas, G.O., Verplanken, B.: Old habits die hard: travel habit formation and decay during an office relocation. Environ. Behav. 47(10), 1089-1106 (2015)

Waygood, E.O.D., Sun, Y., Letarte, L.: Active travel by built environment and lifecycle stage: case study of Osaka metropolitan area. Int. J. Environ. Res. Public Health 12(12), 15900-15924 (2015)

Waygood, E.O.D., Friman, M., Taniguchi, A., Olsson, L.E.: Children's life satisfaction and travel satisfaction: evidence from Canada, Japan, and Sweden. Travel Behaviour and Society 16, 214-223 (2019)

Ye, R., Titheridge, H.: Satisfaction with the commute: the role of travel mode choice, built environment and attitudes. Transp. Res. Part D 52B, 535-547 (2017)

Zarabi, Z., Manaugh, K., Lord, S.: The impacts of residential relocation on commute habits: a qualitative perspective on households' mobility behaviors and strategies. Travel Behav. Soc. 16, 131-142 (2019)

Zhu, J., Fan, Y.: Daily travel behavior and emotional well-being: effects of trip mode, duration, purpose, and companionship. Transp. Res. Part A 118, 360-373 (2018)

Publisher's Note Springer Nature remains neutral with regard to jurisdictional claims in published maps and institutional affiliations. 